\title{
Transforming growth factor- $\beta 1$ increases lysyl oxidase expression by downregulating MIR29A in human granulosa lutein cells
}

\author{
Ying Fang ${ }^{1,2}$, Hsun-Ming Chang ${ }^{2}$, Jung-Chien Cheng², Christian Klausen², Peter C K Leung ${ }^{2}$ \\ and Xiaokui Yang ${ }^{1}$ \\ ${ }^{1}$ Department of Human Reproductive Medicine, Beijing Obstetrics and Gynecology Hospital, Capital Medical \\ University, Beijing, China and ${ }^{2}$ Department of Obstetrics and Gynaecology, Child \& Family Research Institute, \\ University of British Columbia, Vancouver, British Columbia, Canada \\ Correspondence should be addressed to P C K Leung or X Yang; Email: peter.leung@ubc.ca or xiaokuiyang2012@163.com
}

\begin{abstract}
Lysyl oxidase (LOX), a key enzyme in the formation and stabilization of the extracellular matrix, is expressed in granulosa cells and plays a critical role in the regulation of granulosa cell differentiation, oocyte maturation and ovulation. To date, the regulation of LOX expression in human granulosa cells remains largely unknown. In this study, using primary and immortalized human granulosa lutein cells, we demonstrated that transforming growth factor (TGF)- $\beta 1$ (TGFB1) upregulated LOX expression and downregulated microRNA-29a (MIR29A) expression via a TGF- $\beta$ type I receptor-mediated signaling pathway. Additionally, we showed that MIR29A downregulated the expression of LOX in both types of cells. Furthermore, the downregulation of MIR29A contributed to the TGFB1-induced increase in LOX expression because the inhibition of MIR29A with a MIR29A inhibitor not only reversed the MIR29A-induced downregulation of LOX but also enhanced the TGFB1-induced upregulation of LOX. Our findings suggest that TGFB1 and MIR29A may play essential roles in the regulation of extracellular matrix remodeling during the periovulatory phase. Reproduction (2016) 152 205-213
\end{abstract}

\section{Introduction}

Lysyl oxidase (LOX) is characterized by the ability to form and maintain the extracellular matrix (ECM) by initiating the covalent cross-linking of collagen and elastin during follicular development (Kagan \& Trackman 1991, Smith-Mungo \& Kagan 1998). Recent studies have shown that LOX is expressed in granulosa cells (Kendall et al. 2003), and this enzyme may play a critical role in the regulation of granulosa cell differentiation, oocyte maturation and ovulation (Slee et al. 2001, Jiang et al. 2010). In perch ovary, LOX mRNA levels were dramatically increased during ovulation (Langenau et al. 1999). In rabbit ovarian follicles, the activity of LOX reached its peak after human chorionic gonadotropin-induced follicle rupture (Himeno 1986). Indeed, the disruption of LOX activity has been shown to be related to copper-responsive subfertility due to abnormal follicular growth (Kendall et al. 2003). In rats, the expression of LOX in mural granulosa cells was strongly associated with the developmental competence of oocytes, indicating that LOX can be used as a potential marker for the quality of oocytes in assisted reproduction (Jiang et al. 2010). In view of the significant role of LOX in folliculogenesis, a growing number of studies have focused on the regulation of Lox at both the endocrine and paracrine levels. In rat granulosa cells, Lox mRNA levels and enzyme activity were suppressed by FSH and 8-bromo-cAMP in a dose-dependent manner, whereas they were strongly enhanced by dihydrotestosterone (DHT). However, DHT enhanced the FSH-induced suppressive effect on Lox mRNA levels (Slee et al. 2001, Harlow et al. 2003). Many locally produced growth factors, such as transforming growth factor- $\beta 1$ (TGFB1), growth differentiation factor- 9 and activin A, have been reported to stimulate $L O X$ mRNA expression and activity (Harlow et al. 2003). Interestingly, Lox mRNA levels were increased more than threefold in a DHEAinduced rat polycystic ovary model (Henmi et al. 2001). In the DES-primed immature rat ovary, equine chorionic gonadotropin treatment significantly suppressed LOX transcripts, and this suppressive effect was further enhanced during gonadotropin-induced luteinization, suggesting that the expression of LOX is inversely related to the granulosa cell differentiation (Slee et al. 2001). To date, the regulation of LOX expression in human granulosa cells remains to be elucidated. 
TGFB1, a canonical member of the TGF- $\beta$ superfamily, is expressed and secreted by growing follicles, including oocytes, theca cells and granulosa cells (Knight \& Glister 2006). In mammals, this growth factor plays a critical role in the regulation of follicular development and oocyte maturation (Ingman et al. 2006, Pangas 2007). Higher serum levels and increased ovarian expression of TGFB1 have been found in patients with polycystic ovary syndrome (PCOS), indicating that the dysregulation of TGFB1 may be involved in the pathogenesis of PCOS (Raja-Khan et al. 2010, Hatzirodos et al. 2011, Tal et al. 2013). MicroRNAs (miRNAs) are endogenous small noncoding RNAs that negatively regulate gene expression by binding to specific mRNAs and promoting their degradation and/or translational repression (Bartel 2004). MicroRNA-29a (MIR29A), one of the earliest identified miRNA families, is strongly expressed in the ovaries of mammals, including humans (Hossain et al. 2009, da Silveira et al. 2012, Sang et al. 2013). MIR29A is expressed in bovine oocytes and follicular cells (cumulus/granulosa cells and theca cells) and can be detected in the follicular fluid at different developmental phases. Notably, MIR29A is implicated in the regulation of cell-cell communication (oocytes and granulosa cells), progesterone production and luteinization (Hossain et al. 2009). Clinical data have shown that MIR29A levels are reduced in the serum of PCOS patients (Ding et al. 2015). Interestingly, emerging results from in vitro studies have demonstrated that the expression of MIR29A is downregulated by TGFB1 in many cell types, including fibroblasts and tubular epithelial cells (Maurer et al. 2010, Qin et al. 2011, Wang et al. 2012, Yang et al. 2013). Given that PCOS patients have higher expression levels of TGFB1 and LOX as well as lower expression levels of MIR29A, we hypothesized that TGFB1 increases the expression of LOX by downregulating MIR29A in human granulosa cells. In this study, using primary and immortalized human granulosa lutein cells, we sought to investigate the biological role of TGFB1 in the regulation of LOX expression and the underlying molecular mechanisms.

\section{Materials and methods}

\section{Preparation of primary human granulosa lutein cells}

Primary human granulosa lutein (hGL) cells were collected after obtaining informed consent from patients and approval from the University of British Columbia Research Ethics Board. The controlled ovarian stimulation protocol for in vitro fertilization patients consisted of downregulation of either luteal-phase nafarelin acetate (Synarel; Pfizer) or follicularphase GnRH antagonist (Ganirelix; Merck, Frosst, Montreal, Canada). Gonadotropin stimulation began on menstrual cycle day 2 with human menopausal gonadotropin (hMG; Menopur, Ferring) and recombinant FSH (Puregon, Merck, Montreal,
Canada) and was followed by human chorionic gonadotropin (Pregnyl, Merck, Montreal, Canada) administration 34-36 h before oocyte retrieval, based on the follicle size. Follicular aspirates from women undergoing oocyte retrieval were density centrifuged as described previously and hGL cells were then purified (Quinn et al. 2006, Chang et al. 2013). Individual primary cultures comprised cells from one patient. Then, $2 \times 10^{5}$ viable cells were seeded per well in 12 well plates and cultured in a humidified atmosphere of $5 \% \mathrm{CO}_{2}$ and $95 \%$ air at $37^{\circ} \mathrm{C}$. The cells were cultured in Dulbecco's modified Eagle's medium/nutrient mixture F-12 Ham (DMEM/F-12; Sigma-Aldrich) supplemented with $10 \%$ charcoal/dextrantreated fetal bovine serum (HyClone, Logan, UT, USA), $100 \mathrm{U} / \mathrm{mL}$ of penicillin (Life Technologies, Inc/BRL), $100 \mu \mathrm{g} / \mathrm{mL}$ of streptomycin sulfate (Life Technologies), and 1X GlutaMAX (Life Technologies). The culture medium was changed every other day in all of the experiments.

\section{Human granulosa cell immortalized with Simian virus 40 large $T$ antigen}

A non-tumorigenic immortalized human granulosa lutein cell line (SVOG), which was previously established by transfecting human granulosa lutein cells with the SV40 large T antigen (Lie et al. 1996), was used in the present study. SVOG cells retain the physiological characteristics of hGL cells, such as the steroidogenic function, and also respond to many different treatments in a similar manner as hGL cells (Chang et al. 2014, 2015a,b, Chen et al. 2015). SVOG cells were counted with a hemocytometer, and cell viability was assessed using Trypan blue $(0.04 \%)$ exclusion. The cells were seeded $\left(4-8 \times 10^{5}\right.$ cells per well in 6-well plates) and cultured in DMEM/F-12 medium supplemented with $10 \%$ charcoal/dextran-treated fetal bovine serum (HyClone), $100 \mathrm{U} / \mathrm{mL}$ of penicillin (Life Technologies), $100 \mu \mathrm{g} / \mathrm{mL}$ of streptomycin sulfate (Life Technologies) and $1 \mathrm{X}$ GlutaMAX (Life Technologies) in a humidified incubator at $37^{\circ} \mathrm{C}$ with $5 \% \mathrm{CO}_{2}$. The culture medium was changed every other day for all of the experiments, and the cells were maintained in serum-free medium for $24 \mathrm{~h}$ before treatment with growth factor.

\section{miRNA and miRNA inhibitor transfection}

SVOG cells were seeded in 6 well plates until 50-60\% confluence was reached on the day of transfection. Cells were transfected with $25 \mathrm{nM}$ MIR29A mimic, $25 \mathrm{nM}$ miR negative control, $25 \mathrm{nM}$ MIR29A inhibitor or $25 \mathrm{nM}$ inhibitor negative control (Ambion) using Lipofectamine RNAiMAX (Life Technologies) as a transfection reagent, according to the manufacturer's instructions. The MIR29A mimic is a small, double-stranded RNA molecule that mimics mature endogenous MIR29A, while the MIR29A inhibitor is a single-stranded RNA oligonucleotide that is antisense to the endogenous MIR29A. The inhibitor negative control is a scrambled nonspecific sequence with no identifiable effects on any reported miRNA function. The medium was changed to DMEM-F12 containing 10\% FBS the day after transfection. The transfected cells were harvested at the indicated time points following specific treatments. 


\section{Antibodies and reagents}

Recombinant human TGFB1 was obtained from R\&D Systems as a Chinese hamster ovary cell-derived protein of more than $97 \%$ purity based on sodium dodecyl sulfate polyacrylamide gel electrophoresis (SDS-PAGE). Lyophilized TGFB1 was reconstituted in a solution of $4 \mathrm{mM} \mathrm{HCl}$ with $0.1 \%$ BSA as a carrier protein. The TGF- $\beta$ type I receptor inhibitor SB431542 (S4317) was purchased from SigmaAldrich. Monoclonal mouse anti- $\alpha$-tubulin antibody (sc-23948; diluted 1:2000) was obtained from Santa Cruz Biotechnology. The polyclonal rabbit anti-LOX (ab31238) antibody (diluted 1:1000) was obtained from Abcam. The horseradish peroxidase-conjugated goat anti-rabbit and goat anti-mouse immunoglobulin G antibodies were obtained from Bio-Rad Laboratories.

\section{Reverse transcription quantitative real-time PCR (RT-qPCR)}

Total RNA was extracted with TRIzol Reagent (Life Technologies) in accordance with the manufacturer's instructions. Briefly, for the mRNA assay, RNA $(2 \mu \mathrm{g})$ was reverse transcribed into first-strand cDNA with random primers and Moloney murine leukemia virus (MMLV) reverse transcriptase (Promega). RT-qPCR was performed on Applied Biosystems 7300 RealTime PCR System in 96 well optical reaction plates. Each $20 \mu \mathrm{L}$ RT-qPCR reaction contained 1X SYBR Green PCR Master Mix (Applied Biosystems), $20 \mathrm{ng}$ CDNA and $250 \mathrm{nM}$ of each specific primer. The primers used were $L O X, 5^{\prime}$-GCCTCAGGCTGCAC AATTTC-3' (sense) and 5'-TCAGAACACCAGGCACTGATTT-3' (antisense); and glyceraldehyde-3-phosphate dehydrogenase (GAPDH), 5'-GAGTCAACGGATTTGGTCGT-3' (sense) and 5'-GACAAGCTTCCCGTTCTCAG-3' (antisense). The specificity of each assay was validated using dissociation curve analysis and agarose gel electrophoresis of the PCR products. The assay performance was validated by evaluating amplification efficiencies using calibration curves and ensuring that the plot of the log input amount vs $\Delta \mathrm{Cq}$ (also known as $\Delta \mathrm{Ct}$ ) had a slope $<|0.1|$.

For the miRNA assay, $1 \mu \mathrm{g}$ RNA was reverse transcribed into cDNA using MultiScribe Reverse Transcriptase from the TaqMan MicroRNA RT Kit (Applied Biosystems) and specific stem-loop RT primers of MIR29A and U6 small nuclear RNA from TaqMan microRNA assays (Applied Biosystems). RT-qPCR was performed on the Applied Biosystems 7300 Real-Time PCR System in 96 well optical reaction plates. The TaqMan microRNA assays were used to detect the expression level of MIR29A according to the manufacturer's instructions. Each $20 \mu \mathrm{L}$ RT-qPCR reaction contained 1X TaqMan Universal PCR Master Mix II, TaqMan Small RNA Assay for MIR29A and U6 (Applied Biosystems), and 20 ng cDNA. Three independent experiments were performed on different cultures, and each sample was assayed in triplicate. Mean value was used for the determination of mRNA levels by the comparative Cq method with GAPDH or U6 as the reference gene and using the formula $2^{-\triangle \Delta \mathrm{Cq}}$. GAPDH and $U 6$ levels were unaffected by the various treatments in our study.

\section{Western blotting analysis}

Cells were washed with cold PBS and lysed in lysis buffer (Cell Signaling Technology) containing a protease inhibitor cocktail (Sigma-Aldrich). Extracts were centrifuged at $20,000 \mathrm{~g}$ for $10 \mathrm{~min}$ at $4^{\circ} \mathrm{C}$, and protein concentrations were determined using the DC Protein Assay (Bio-Rad Laboratories). Equal amounts of protein $(50 \mu \mathrm{g})$ were separated on $10 \%$ SDS-PAGE gels and transferred onto polyvinylidene fluoride membranes. After $1 \mathrm{~h}$ of blocking in Tris-buffered saline containing $0.05 \%$ Tween 20 and $5 \%$ nonfat dried milk, the membranes was then incubated overnight at $4^{\circ} \mathrm{C}$ with the relevant primary antibodies. After washing, the membranes were incubated with a peroxidaseconjugated secondary antibody (Bio-Rad Laboratories) for $1 \mathrm{~h}$. Immunoreactive bands were detected using enhanced chemiluminescence reagents or SuperSignal West Femto chemiluminescence substrate (Pierce), followed by exposure to CL-XPosure film (Thermo Fisher). Membranes were stripped with stripping buffer $(50 \mathrm{mM}$ Tris- $\mathrm{HCl}$
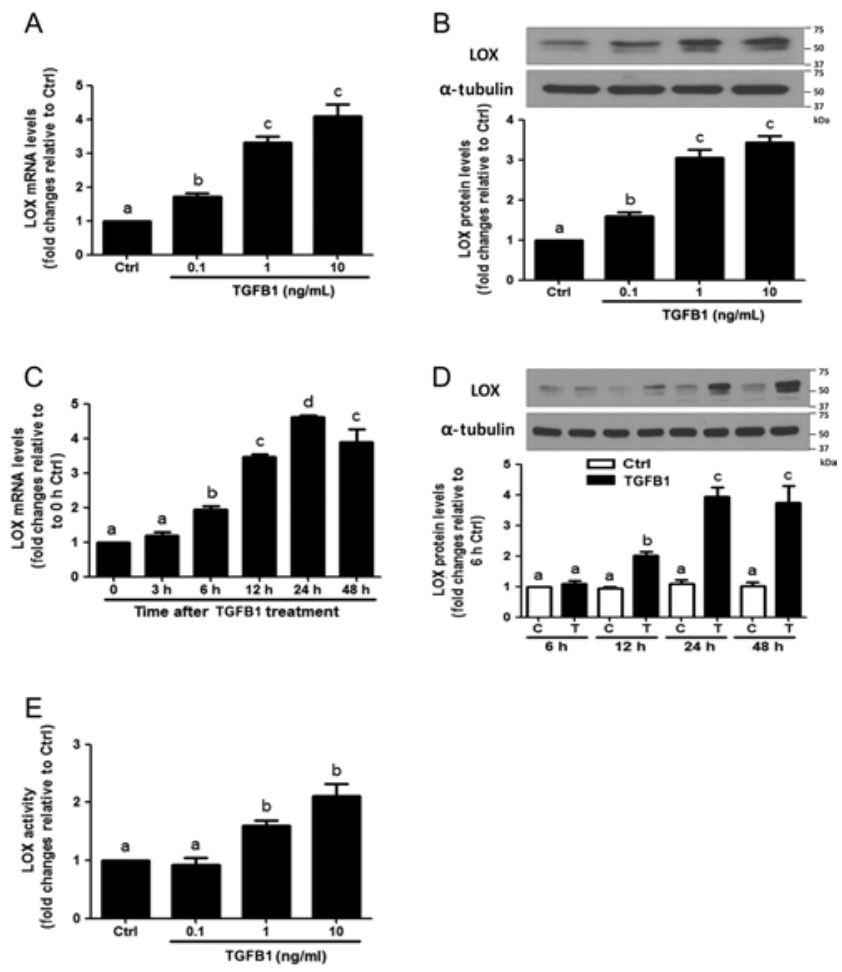

Figure 1 TGFB1 induces the upregulation of LOX expression and activity in SVOG cells. (A and B) SVOG cells were treated with vehicle control or increasing concentrations $(0.1,1$ or $10 \mathrm{ng} / \mathrm{mL})$ of TGFB1 for $12 \mathrm{~h}$ or $24 \mathrm{~h}$, and LOX mRNA (A) or protein levels (B) were examined using RT-qPCR or Western blotting. (C and D) SVOG cells were treated with $5 \mathrm{ng} / \mathrm{mL}$ of TGFB1 for $0,3,6,12,24$ and $48 \mathrm{~h}$, and LOX mRNA (C) or protein (for 6, 12, 24 and $48 \mathrm{~h}$ ) (D) levels were examined using RT-qPCR or Western blotting. (E) SVOG cells were treated for $24 \mathrm{~h}$ with increasing concentrations of TGFB1 $(0.1,1$ or $10 \mathrm{ng} / \mathrm{mL})$ and LOX activity in conditioned medium was determined using a fluorescent enzyme assay. The results are presented as the mean \pm S.E.M. from at least 3 independent experiments, and values without a common letter are significantly different $(P<0.05)$. Ctrl, control. 
A

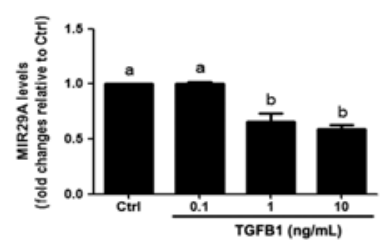

C
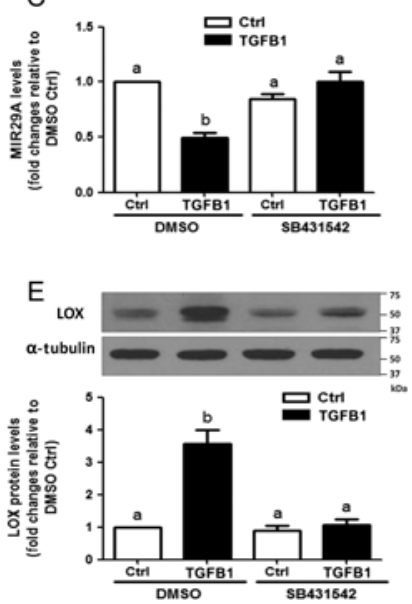

Figure 2 SB431542 reverses the TGFB1-induced downregulation of MIR29A, and abolishes the TGFB1-induced upregulation of LOX (A) SVOG cells were treated with vehicle control or increasing concentrations $(0.1,1$ or $10 \mathrm{ng} / \mathrm{mL})$ of TGFB1 for $12 \mathrm{~h}$, and the expression level of MIR29A was examined using RT-qPCR. (B) SVOG cells were treated with $5 \mathrm{ng} / \mathrm{mL}$ of TGFB1 for $0,3,6,12,24$ and $48 \mathrm{~h}$ and the expression level of MIR29A was examined by RT-qPCR. (C, D and E) Cells were treated with $5 \mathrm{ng} / \mathrm{mL}$ of TGFB1 for $12 \mathrm{~h}(\mathrm{C})$, $12 \mathrm{~h}(\mathrm{D})$ or $24 \mathrm{~h}(\mathrm{E})$ in the presence of vehicle control (DMSO) or $10 \mu \mathrm{M}$ SB431542, and the expression level of MIR29A (C) and LOX (D) mRNA were examined using RT-qPCR, and LOX protein (E) levels were examined using Western blotting. The results are presented as the mean \pm S.E.M. from at least 3 independent experiments, and values without a common letter are significantly different $(P<0.05)$.

$\mathrm{pH} 7.6,10 \mathrm{mmol} / \mathrm{L} \beta$-mercaptoethanol and $1 \%$ SDS) at $50^{\circ} \mathrm{C}$ for $30 \mathrm{~min}$ and then reprobed with mouse anti- $\alpha$ tubulin antibody as a loading control. Immunoreactive band intensities were quantified by densitometry (Scion Image software, Scion Corporation, Frederick, MD, USA), target levels were normalized to those of $\alpha$-tubulin, and the results are expressed as fold change relative to the respective control.

\section{Measurement of LOX activity}

Following the specified treatment, culture medium was assayed immediately or stored at $-80^{\circ} \mathrm{C}$ until it was assayed. Relative quantification of LOX activity was performed according to the manufacturer's instructions using a fluorescent enzyme assay (Abcam, ab112139). The coefficient of variation for this assay was $7.94 \%$ and the reported detection limit of LOX in solution is $40 \mathrm{ng}$. Each sample was measured in triplicate and LOX activity was normalized to total cellular protein content for each sample, and the results are expressed as fold change relative to the respective control.

\section{Statistical analysis}

PRISM software (GraphPad Software) was used to perform Student's t-test or one-way ANOVA followed by Tukey's multiple comparison tests. The results are presented as the mean \pm S.E.M. of at least three independent experiments performed on different cultures and were considered significantly different if $P<0.05$.

\section{Results}

\section{TGFB1 induces the upregulation of LOX expression and activity in SVOG cells}

It has been shown that TGFB1 can stimulate LOX mRNA and enzyme activity in rat granulosa cells (Harlow et al. 2003). However, neither the regulation nor the potential mechanism has been defined in human granulosa cells. To examine whether TGFB1 can regulate the expression of LOX in human granulosa cells, SVOG cells were treated with a vehicle control or increasing concentrations $(0.1,1$ or $10 \mathrm{ng} / \mathrm{mL})$ of human recombinant TGFB1. As shown in Fig. 1A, treatment with TGFB1 for $12 \mathrm{~h}$ increased the LOX mRNA levels in a concentration-dependent manner. Consistent with the results from mRNA, treatment with TGFB1 increased LOX protein levels (Fig. 1B). As shown in Fig. 1C, the time course experiments following TGFB1 treatment demonstrated that LOX mRNA levels began to increase $6 \mathrm{~h}$ after treatment, reaching a peak level at $24 \mathrm{~h}$, and the effect was sustained until $48 \mathrm{~h}$ after treatment. Western blotting analysis revealed that LOX protein levels increased starting at $12 \mathrm{~h}$, and persisted until $48 \mathrm{~h}$ after treatment (Fig. 1D). To investigate whether TGFB1-induced upregulation of LOX expression correlates with an increase in LOX activity, we used a fluorescent enzyme assay to measure LOX activity in conditioned medium following treatment of SVOG cells with increasing concentrations of TGFB1. The results showed that TGFB1 could significantly increase the LOX activity in a concentration-dependent manner (Fig. 1E).

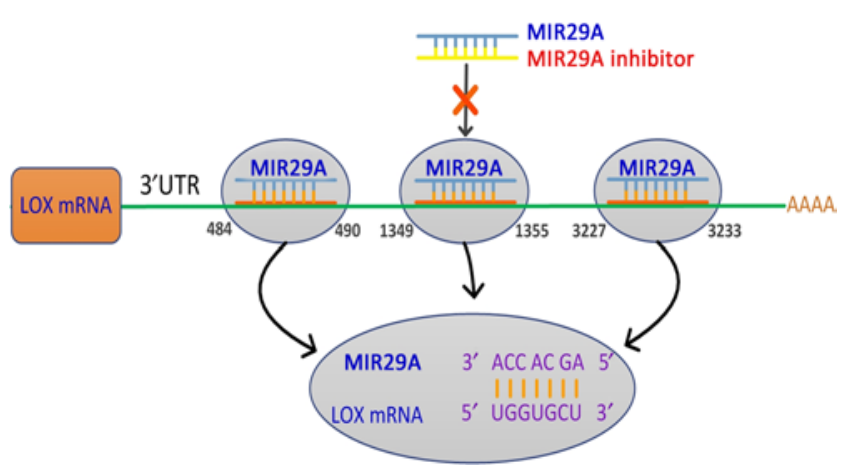

Figure 3 Schematic diagram representing the consequential pairing of the LOX region and MIR29A using the TargetScan program. 
A
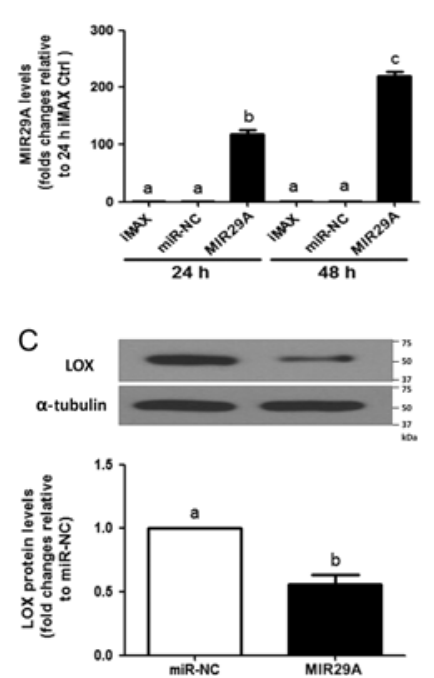

Figure 4 MIR29A inhibits the expression and activity of LOX in human granulosa cells. (A) SVOG cells were transfected with $25 \mathrm{nM}$ Lipofectamine RNAiMAX, miR-NC or MIR29A mimic for $24 \mathrm{~h}$ or $48 \mathrm{~h}$, and the transfection efficiency was examined using RT-qPCR. (B, C and D) SVOG cells were transfected for $24 \mathrm{~h}$ with $25 \mathrm{nM}$ miR-NC and MIR29A mimic for $24 \mathrm{~h}$ and LOX mRNA (B), protein (C) and activity (D) were measured by RT-qPCR, Western blotting and fluorescent enzyme assay, respectively. The results are presented as the mean \pm S.E.M. from at least 3 independent experiments, and values without a common letter are significantly different $(P<0.05)$. IMAX, lipofectamine RNAiMAX; miR-NC, miRNA mimic negative control; MIR29A, MIR29A mimic.

\section{TGFB1 downregulates the expression of MIR29A}

Recent studies have shown that TGFB1 could suppress the expression of MIR29A in the fibroblasts, tubular epithelial cells and primary chondrocytes (Maurer et al. 2010, Qin et al. 2011, Wang et al. 2012, Yang et al. 2013). To date, no study has investigated the regulatory effect of TGFB1 on MIR29A expression in human granulosa cells. To address this issue, we treated SVOG cells with a vehicle control or different concentrations $(0.1,1$ or $10 \mathrm{ng} / \mathrm{mL})$ of TGFB1, and the results showed that TGFB1 decreased MIR29A levels in a concentrationdependent manner (Fig. 2A). In addition, time course studies revealed that MIR29A level began to decrease as early as $6 \mathrm{~h}$ after TGFB1 treatment, and the suppressive effect was sustained until $48 \mathrm{~h}$ after treatment (Fig. 2B).

\section{TGF- $\beta$ type I receptor is required for the TGFB1-induced downregulation of MIR29A and upregulation of $L O X$}

A potent and specific TGFB1 type I receptor inhibitor, SB431542, was used to verify the involvement of the receptor in the effects of TGFB1 (Inman et al. 2002). As shown in Fig. 2C, pretreatment with SB431542 reversed the downregulation of MIR29A caused by TGFB1. Similarly, the stimulatory effects of TGFB1 on the expression of LOX (mRNA and protein) were completely abolished by pretreatment with SB431542 (Fig. 2D and E).

\section{MIR29A inhibits the expression and activity of LOX}

We used the TargetScan database to predict the potential binding sites of MIR29A in the LOX mRNA 3'-UTR region (Fig. 3). A previous study identified a direct interaction between the upregulated $L O X$ mRNA and the downregulated MIR29A in anaplastic thyroid carcinomas, which was experimentally validated by a luciferase assay in HEK cells (Hebrant et al. 2014). To examine whether MIR29A can inhibit the expression of LOX in human granulosa cells, we first transfected SVOG cells with a MIR29A mimic or a miRNA mimic negative control at a final concentration of $25 \mathrm{nM}$ for 24 or $48 \mathrm{~h}$. The transfection efficiency was examined using RT-qPCR. As shown in Fig. 4A, the intracellular MIR29A levels were increased by more than 100 -fold at $24 \mathrm{~h}$ and 200 -fold at $48 \mathrm{~h}$ after transfection. Next, we investigated the regulatory role of MIR29A on the expression of LOX in human granulosa cells. As shown in Fig. $4 \mathrm{~B}$ and C,
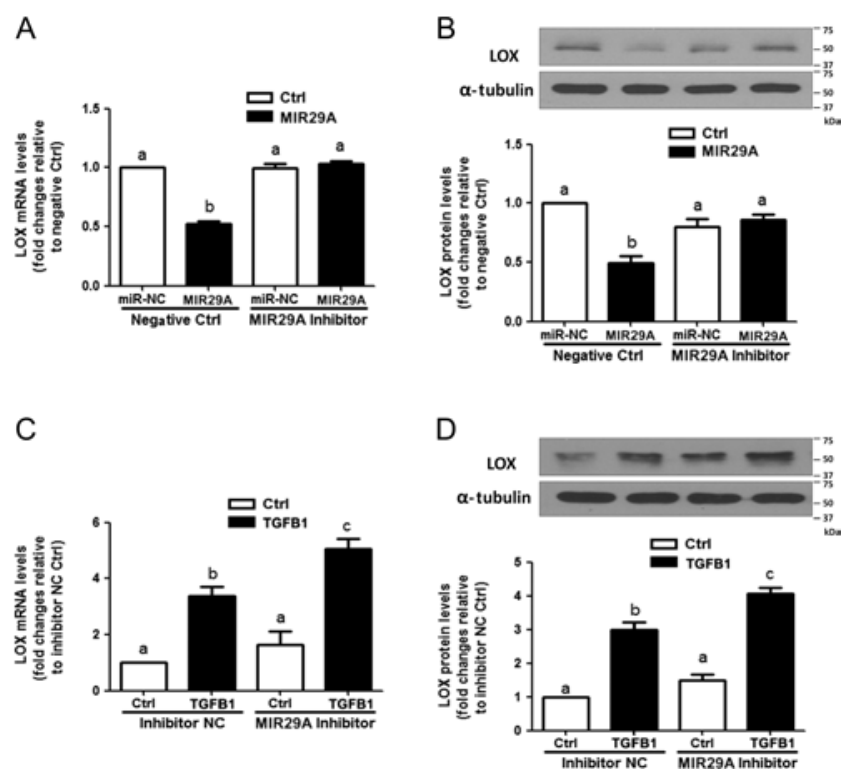

Figure 5 The downregulation of MIR29A contributes to the TGFB1-induced increase in LOX expression. (A and B) SVOG cells were transfected for $24 \mathrm{~h}$ with $25 \mathrm{nM}$ of miRNA inhibitor negative control or $25 \mathrm{nM}$ of MIR29A inhibitor before the transfection with miR-NC or MIR29A mimic for additional $24 \mathrm{~h}$. The LOX mRNA (A) or protein levels (B) were examined using RT-qPCR or Western blotting. (C and D) SVOG cells were transfected with $25 \mathrm{nM}$ of miRNA inhibitor negative control or $25 \mathrm{nM}$ of MIR29A inhibitor for $24 \mathrm{~h}$, and then treated with vehicle control or $5 \mathrm{ng} / \mathrm{mL}$ of TGFB1 for additional $24 \mathrm{~h}$. The LOX mRNA (C) and protein levels (D) were examined using RT-qPCR or Western blotting. The results are presented as the mean \pm S.E.M. from at least 3 independent experiments, and values without a common letter are significantly different $(P<0.05)$. Ctrl, control; inhibitor NC, miRNA inhibitor negative control; miR-NC, miRNA mimic negative control; MIR29A, MIR29A mimic. 
A

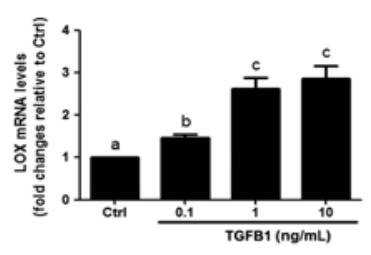

c

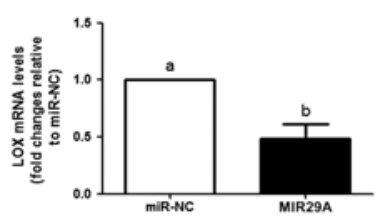

B เox
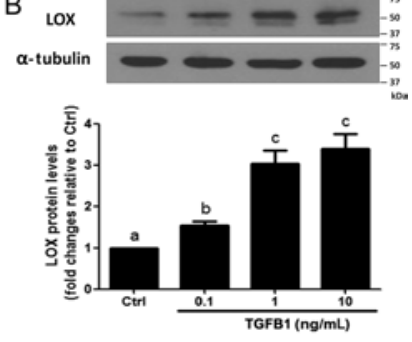

$D_{\operatorname{cox}}$
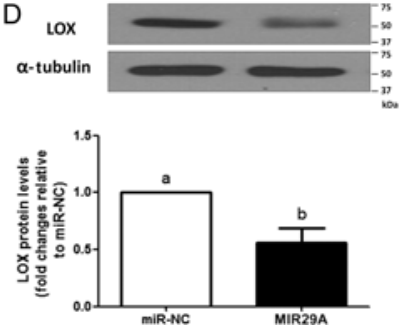

Figure 6 Effects of TGFB1 and MIR29A on the regulation of LOX in primary hGL cells. (A and B) Primary hGL cells were treated with vehicle control or increasing concentrations $(0.1,1$ or $10 \mathrm{ng} / \mathrm{mL})$ of TGFB1 for $12 \mathrm{~h}$ or $24 \mathrm{~h}$, and LOX mRNA (A) or protein levels (B) were examined using RT-qPCR or Western blotting. (C and D) Primary hGL cells were transfected with miR-NC or MIR29A mimic for $24 \mathrm{~h}$, and the levels of LOX mRNA (C) and protein (D) were examined using RT-qPCR or Western blotting. The results are presented as the mean \pm S.E.M. from at least 3 independent experiments, and values without a common letter are significantly different $(P<0.05)$. Ctrl, control; hGL, human granulosa-lutein.

transfection with the MIR29A mimic for $24 \mathrm{~h}$ resulted in significant decreases in the levels of LOX mRNA and protein. Furthermore, compared with the miRNA mimic negative control, transfection of SVOG cells with the MIR29A mimic for $24 \mathrm{~h}$ significantly decreased LOX activity in conditioned medium (Fig. 4D).

\section{Downregulation of MIR29A contributes to TGFB1-induced increase in LOX expression}

To further confirm the role of MIR29A in the suppression of LOX expression, we treated SVOG cells with a miRNA inhibitor negative control or the MIR29A inhibitor for $24 \mathrm{~h}$ before transfection with the miRNA mimic negative control or the MIR29A mimic. Our results show that the decreases in LOX mRNA (Fig. 5A) and LOX protein (Fig. 5B) levels induced by the MIR29A mimic were reversed by transfection with a MIR29A inhibitor. Next, we investigated whether MIR29A plays a role in the TGFB1-induced upregulation of LOX expression. The SVOG cells were transfected with the miRNA inhibitor negative control or the MIR29A inhibitor for $24 \mathrm{~h}$ before treatment with $5 \mathrm{ng} / \mathrm{mL}$ of TGFB1 (additional $24 \mathrm{~h})$. The results showed that the stimulatory effects of TGFB1 (5 ng/mL) on LOX mRNA (Fig. 5C) and protein (Fig. 5D) levels were further enhanced by the MIR29A inhibitor, which suppressed the effects from the endogenous MIR29A.

\section{Effects of TGFB1 and MIR29A on the regulation of LOX in primary hGL cells}

Non-immortalized primary hGL cells were used to further confirm the regulatory effects of TGFB1 and MIR29A on the expression of LOX. As shown in Fig. 6A and $\mathrm{B}$, treatment of primary hGL cells with TGFB1 (0.1, 1 or $10 \mathrm{ng} / \mathrm{mL}$ ) increased LOX mRNA (12 h) and protein levels $(24 \mathrm{~h})$ in a concentration-dependent manner. Consistent with the results from SVOG cells, transfection with MIR29A mimic for $24 \mathrm{~h}$ significantly decreased the levels of LOX mRNA and protein in primary hGL cells (Fig. 6C and D).

\section{Discussion}

The ECM in the ovary plays an essential role in follicular growth and subsequent ovulation (Woodruff \& Shea 2007). LOX, a key enzyme involved in the remodeling and stabilization of the ECM, has been shown to be closely associated with granulosa cell differentiation, oocyte maturation and ovulation. TGFB1 has been identified as a key regulator of LOX expression and activity in many cell types, including lung fibroblasts (Boak et al. 1994), osteoblasts (Feres-Filho et al. 1995) and aortic smooth muscle cells (Gacheru et al. 1997). In gingival fibroblastic cells, TGFB1 strongly induced the expression of connective tissue growth factor (CTGF) and LOX, and CTGF itself increased the LOX enzyme activity up to 1.5-fold (Hong et al. 1999). Additionally, TGFB1 inhibited cell proliferation by increasing LOX mRNA and protein levels in neonatal rat aortic smooth muscle cells (Gacheru et al. 1997). Furthermore, signaling studies have found that both SMAD-dependent and -independent (e.g. JNK/AP-1, $\mathrm{PI3K} / \mathrm{Akt}$, and MAPK) signaling pathways were involved in the regulation of LOX induced by TGFB1 in cardiac fibroblasts and human trabecular meshwork cells (Sethi et al. 2011, Voloshenyuk et al. 2011). A recent study revealed that LOX mRNA and enzyme activities were induced by TGFB1 in a dose-dependent manner in rat granulosa cells (Harlow et al. 2003). However, the underlying mechanism by which TGFB1 regulates LOX expression was not investigated in these studies. In the present study, we demonstrated that TGFB1 upregulated the expression of LOX (both mRNA and protein) and increased LOX activity in human granulosa lutein cells. Furthermore, we showed that downregulation of MIR29A contributed to the TGFB1induced upregulation of LOX. These conclusions are based on the fact that the downregulation of MIR29A induced by TGFB1 occurred at $6 \mathrm{~h}$ after treatment, while the upregulation of LOX started later, at $12 \mathrm{~h}$ (mRNA level) and at $24 \mathrm{~h}$ (protein level). In addition, the inhibition of MIR29A using a specific inhibitor not only reversed the MIR29A-induced downregulation of LOX but also enhanced the TGFB1-induced 
upregulation of LOX. Our results indicate that MIR29A may act as a downstream negative regulator for the intracellular function of TGFB1 in human granulosa cells.

MIR29A is expressed in granulosa cells at various follicular stages and plays an essential role in folliculogenesis. Studies have shown that the gonadotropins (FSH and $\mathrm{LH}$ ) regulate MIR29A in a biphasic manner. Notably, treatment with FSH for $12 \mathrm{~h}$ decreased the expression of MIR29A, while treatment with FSH for $48 \mathrm{~h}$ caused a twofold increase in MIR29A expression (Yao et al. 2010). In addition to gonadotropins, many growth factors have been shown to regulate the expression of MIR29A. In particular, TGFB1 $(10 \mathrm{ng} / \mathrm{mL})$ suppressed the expression of MIR29A up to $60 \%$ in human orbital fibroblasts in a time-dependent manner (Tan et al. 2014). Another study has revealed the involvement of TGFB1/Smad3 signaling in the downregulation of miR-29 in cultured fibroblasts and tubular epithelial cells. Notably, the TGFB1-induced downregulation of miR-29 was mediated by the binding of Smad3 to the promoter of miR-29 (Qin et al. 2011). In this study, we demonstrated for the first time that TGFB1 negatively regulates the expression of MIR29A in human granulosa cells. Future research will focus on how TGFB1 downregulates the expression of MIR29A in human granulosa cells.

In a rat model of premature ovarian failure (POF), the expression of MIR29A was substantially lower in POF ovaries than in normal ovaries, suggesting a role for the deregulation of MIR29A in POF development (Kuang et al. 2014). In addition, serum levels of MIR29A were lower in PCOS patients (Ding et al. 2015). These results indicate that deregulation of MIR29A may lead to several ovarian disorders. Interestingly, compelling evidence has shown that the deregulation of TGFB1 is also involved in the pathogenesis of PCOS (RajaKhan et al. 2010, Hatzirodos et al. 2011, Tal et al. 2013). Furthermore, the levels of LOX mRNA and protein were upregulated in DHT-treated rat granulosa cells (Harlow et al. 2003) and DHEA-treated PCOS rat ovaries (Henmi et al. 2001). Using in vitro cell models, we have provided a potential molecular mechanism by which TGFB1 positively regulates LOX expression by downregulating the expression of MIR29A in human granulosa cells. Our findings may help explain the molecular changes that often occur in PCOS patients and may lead to the development of novel therapeutic strategies.

It is well known that miRNAs function posttranscriptionally as negative regulators of target gene expression. Using the TargetScan database, we found three potential binding sites for MIR29A in the 3'-UTR of LOX mRNA. Importantly, our in vitro studies demonstrated that LOX mRNA and protein levels were suppressed by MIR29A mimic treatment, and the effect was reversed by the MIR29A inhibitor, suggesting a functional role for MIR29A in the regulation of LOX expression. Indeed, previous studies using 3'-UTR luciferase assays demonstrated a direct interaction of LOX mRNA and MIR29A in HEK293 cells (Hebrant et al. 2014). Taken together, previous studies and our results suggest that MIR29A may downregulate LOX mRNA through a direct interaction with its 3'-UTR site in human granulosa cells. However, MIR29A is not the sole regulator of basal LOX expression because transfection with MIR29A mimic yielded only a 2-fold reduction in LOX despite 100-200-fold increases in MIR29A levels. Furthermore, the addition of a MIR29A inhibitor in the presence of TGFB1 induced a further increase in LOX expression. These findings suggest that there are likely other mechanisms by which TGFB1 upregulates LOX expression, which will be an interesting area for future investigation.

In summary, we demonstrated that TGFB1 not only upregulated the expression and activity of LOX but also downregulated the expression of MIR29A in human granulosa cells. In addition, our results indicate that the TGF- $\beta$ type I receptor is required for these actions induced by TGFB1. Furthermore, the downregulation of MIR29A contributed to the TGFB1-induced upregulation of LOX. Our in vitro findings suggest that TGFB1 and MIR29A may play crucial roles in the control of ECM remodeling during the periovulatory stage.

\section{Declaration of interest}

The authors declare that there is no conflict of interest that could be perceived as prejudicing the impartiality of the research reported.

\section{Funding}

This work was supported by an operating grant (\#143317) from the Canadian Institutes of Health Research to P C K L, the Natural Science Foundation of China (81170542, 81471431) and the Beijing Natural Science Foundation (7152055) to X Y. $X Y$ is the recipient of 'the Health Excellent Talent Foundation of Beijing' from the Beijing Health Bureau (Grant number 2011-3-071).

\section{Acknowledgements}

We thank Dr Elizabeth L Taylor for coordinating the acquisition of patient follicular fluid samples.

\section{References}

Bartel DP 2004 MicroRNAs: genomics, biogenesis, mechanism, and function. Cell 116 281-297. (doi:10.1016/S0092-8674(04)00045-5)

Boak AM, Roy R, Berk J, Taylor L, Polgar P, Goldstein RH \& Kagan HM 1994 Regulation of lysyl oxidase expression in lung fibroblasts by transforming growth factor-beta 1 and prostaglandin E2. American Journal of Respiratory Cell and Molecular Biology 11 751-755. (doi:10.1165/ajrcmb.11.6.7946403) 
Chang HM, Klausen C \& Leung PC 2013 Antimullerian hormone inhibits follicle-stimulating hormone-induced adenylyl cyclase activation, aromatase expression, and estradiol production in human granulosalutein cells. Fertility and Sterility 100 585-592.e1. (doi:10.1016/j. fertnstert.2013.04.019)

Chang HM, Cheng JC, Taylor E \& Leung PC 2014 Oocyte-derived BMP15 but not GDF9 down-regulates connexin43 expression and decreases gap junction intercellular communication activity in immortalized human granulosa cells. Molecular Human Reproduction 20 373-383. (doi:10.1093/molehr/gau001)

Chang HM, Cheng JC, Fang L, Qiu X, Klausen C, Taylor EL \& Leung PC 2015a Recombinant BMP4 and BMP7 downregulate pentraxin 3 in human granulosa cells. Journal of Clinical Endocrinology and Metabolism 100 E365-E374. (doi:10.1210/jc.2014-2496)

Chang HM, Cheng JC, Klausen C \& Leung PC 2015b Recombinant BMP4 and BMP7 increase activin A production by up-regulating inhibin betaA subunit and furin expression in human granulosa-lutein cells. Journal of Clinical Endocrinology and Metabolism 100 E375-E386. (doi:10.1210/ jc.2014-3026)

Chen YC, Chang HM, Cheng JC, Tsai HD, Wu CH \& Leung PC 2015 Transforming growth factor-beta1 up-regulates connexin43 expression in human granulosa cells. Human Reproduction 30 2190-2201. (doi:10.1093/humrep/dev175)

da Silveira JC, Veeramachaneni DN, Winger QA, Carnevale EM \& Bouma GJ 2012 Cell-secreted vesicles in equine ovarian follicular fluid contain miRNAs and proteins: a possible new form of cell communication within the ovarian follicle. Biology of Reproduction $\mathbf{8 6}$ 71. (doi:10.1095/biolreprod.111.093252)

Ding CF, Chen WQ, Zhu YT, Bo YL, Hu HM \& Zheng RH 2015 Circulating microRNAs in patients with polycystic ovary syndrome. Human Fertility 18 22-29. (doi:10.3109/14647273.2014.956811)

Feres-Filho EJ, Choi YJ, Han X, Takala TE \& Trackman PC 1995 Pre- and post-translational regulation of lysyl oxidase by transforming growth factor-beta 1 in osteoblastic MC3T3-E1 cells. Journal of Biological Chemistry 270 30797-30803. (doi:10.1074/jbc.270.51.30797)

Gacheru SN, Thomas KM, Murray SA, Csiszar K, Smith-Mungo LI \& Kagan HM 1997 Transcriptional and post-transcriptional control of lysyl oxidase expression in vascular smooth muscle cells: effects of TGF-beta 1 and serum deprivation. Journal of Cellular Biochemistry 65 395-407. (doi:10.1002/(ISSN)1097-4644)

Harlow CR, Rae M, Davidson L, Trackman PC \& Hillier SG 2003 Lysyl oxidase gene expression and enzyme activity in the rat ovary: regulation by follicle-stimulating hormone, androgen, and transforming growth factor-beta superfamily members in vitro. Endocrinology 144 154-162. (doi:10.1210/en.2002-220652)

Hatzirodos N, Bayne RA, Irving-Rodgers HF, Hummitzsch $K$, Sabatier L, Lee S, Bonner W, Gibson MA, Rainey WE, Carr BR et al. 2011 Linkage of regulators of TGF-beta activity in the fetal ovary to polycystic ovary syndrome. FASEB Journal 25 2256-2265. (doi:10.1096/fj.11-181099)

Hebrant A, Floor S, Saiselet M, Antoniou A, Desbuleux A, Snyers B, La C, de Saint Aubain N, Leteurtre E, Andry G et al. 2014 miRNA expression in anaplastic thyroid carcinomas. PLOS ONE 9 e103871. (doi:10.1371/ journal.pone.0103871)

Henmi H, Endo T, Nagasawa K, Hayashi T, Chida M, Akutagawa N, Iwasaki M, Kitajima Y, Kiya T, Nishikawa A et al. 2001 Lysyl oxidase and MMP-2 expression in dehydroepiandrosterone-induced polycystic ovary in rats. Biology of Reproduction 64 157-162. (doi:10.1095/ biolreprod64.1.157)

Himeno N 1986 [Effect of prostaglandins on collagen synthesis in rabbit ovarian follicles during the ovulatory process]. Nihon Naibunpi Gakkai Zasshi 62 1181-1193. (doi:10.1507/endocrine1927.62.10_1181)

Hong HH, Uzel MI, Duan C, Sheff MC \& Trackman PC 1999 Regulation of lysyl oxidase, collagen, and connective tissue growth factor by TGFbeta1 and detection in human gingiva. Laboratory Investigation $\mathbf{7 9}$ 1655-1667.

Hossain MM, Ghanem N, Hoelker M, Rings F, Phatsara C, Tholen E, Schellander K \& Tesfaye D 2009 Identification and characterization of miRNAs expressed in the bovine ovary. BMC Genomics 10443. (doi:10.1186/1471-2164-10-443)

Ingman WV, Robker RL, Woittiez K \& Robertson SA 2006 Null mutation in transforming growth factor beta1 disrupts ovarian function and causes oocyte incompetence and early embryo arrest. Endocrinology 147 835-845. (doi:10.1210/en.2005-1189)

Inman GJ, Nicolas FJ, Callahan JF, Harling JD, Gaster LM, Reith AD, Laping NJ \& Hill CS 2002 SB-431542 is a potent and specific inhibitor of transforming growth factor-beta superfamily type I activin receptor-like kinase (ALK) receptors ALK4, ALK5, and ALK7. Molecular Pharmacology 62 65-74. (doi:10.1124/mol.62.1.65)

Jiang JY, Xiong H, Cao M, Xia X, Sirard MA \& Tsang BK 2010 Mural granulosa cell gene expression associated with oocyte developmental competence. Journal of Ovarian Research 3 6. (doi:10.1186/1757-2215-3-6)

Kagan HM \& Trackman PC 1991 Properties and function of lysyl oxidase. American Journal of Respiratory Cell and Molecular Biology 5 206-210. (doi:10.1165/ajrcmb/5.3.206)

Kendall NR, Marsters P, Scaramuzzi RJ \& Campbell BK 2003 Expression of lysyl oxidase and effect of copper chloride and ammonium tetrathiomolybdate on bovine ovarian follicle granulosa cells cultured in serum-free media. Reproduction 125 657-665. (doi:10.1530/rep.0.1250657)

Knight PG \& Glister C 2006 TGF-beta superfamily members and ovarian follicle development. Reproduction 132 191-206. (doi:10.1530/ rep.1.01074)

Kuang H, Han D, Xie J, Yan Y, Li J \& Ge P 2014 Profiling of differentially expressed microRNAs in premature ovarian failure in an animal model. Gynecological Endocrinology 30 57-61. (doi:10.3109/09513 590.2013.850659)

Langenau DM, Goetz FW \& Roberts SB 1999 The upregulation of messenger ribonucleic acids during 17alpha, 20beta-dihydroxy4-pregnen-3-one-induced ovulation in the perch ovary. Journal of Molecular Endocrinology 23 137-152. (doi:10.1677/jme.0.0230137)

Lie BL, Leung E, Leung PC \& Auersperg N 1996 Long-term growth and steroidogenic potential of human granulosa-lutein cells immortalized with SV40 large T antigen. Molecular and Cellular Endocrinology 120 169-176. (doi:10.1016/0303-7207(96)03835-X)

Maurer B, Stanczyk J, Jungel A, Akhmetshina A, Trenkmann M, Brock M, Kowal-Bielecka O, Gay RE, Michel BA, Distler JH et al. 2010 MicroRNA-29, a key regulator of collagen expression in systemic sclerosis. Arthritis and Rheumatism 62 1733-1743. (doi:10.1002/ art.27443)

Pangas SA 2007 Growth factors in ovarian development. Seminars in Reproductive Medicine 25 225-234. (doi:10.1055/s-2007-980216)

Qin W, Chung AC, Huang XR, Meng XM, Hui DS, Yu CM, Sung JJ \& Lan HY 2011 TGF-beta/Smad3 signaling promotes renal fibrosis by inhibiting miR-29. Journal of the American Society of Nephrology 22 1462-1474. (doi:10.1681/ASN.2010121308)

Quinn MC, McGregor SB, Stanton JL, Hessian PA, Gillett WR \& Green DP 2006 Purification of granulosa cells from human ovarian follicular fluid using granulosa cell aggregates. Reproduction, Fertility and Development 18 501-508. (doi:10.1071/RD05051)

Raja-Khan N, Kunselman AR, Demers LM, Ewens KG, Spielman RS \& Legro RS 2010 A variant in the fibrillin-3 gene is associated with TGF-beta and inhibin B levels in women with polycystic ovary syndrome. Fertility and Sterility 94 2916-2919. (doi:10.1016/j. fertnstert.2010.05.047)

Sang Q, Yao Z, Wang H, Feng R, Wang H, Zhao X, Xing Q, Jin L, He L, Wu L et al. 2013 Identification of microRNAs in human follicular fluid: characterization of microRNAs that govern steroidogenesis in vitro and are associated with polycystic ovary syndrome in vivo. Journal of Clinical Endocrinology and Metabolism 98 3068-3079. (doi:10.1210/ jc.2013-1715)

Sethi A, Mao W, Wordinger RJ \& Clark AF 2011 Transforming growth factor-beta induces extracellular matrix protein cross-linking lysyl oxidase (LOX) genes in human trabecular meshwork cells. Investigative Ophthalmology and Visual Science 52 5240-5250. (doi:10.1167/ iovs.11-7287)

Slee RB, Hillier SG, Largue P, Harlow CR, Miele G \& Clinton M 2001 Differentiation-dependent expression of connective tissue growth factor and lysyl oxidase messenger ribonucleic acids in rat granulosa cells. Endocrinology 142 1082-1089. (doi:10.1210/en.142.3.1082)

Smith-Mungo LI \& Kagan HM 1998 Lysyl oxidase: properties, regulation and multiple functions in biology. Matrix Biology 16 387-398. (doi:10.1016/S0945-053X(98)90012-9)

Tal R, Seifer DB, Shohat-Tal A, Grazi RV \& Malter HE 2013 Transforming growth factor-beta1 and its receptor soluble endoglin are altered in 
polycystic ovary syndrome during controlled ovarian stimulation. Fertility and Sterility 100 538-543. (doi:10.1016/j.fertnstert.2013.04.022)

Tan J, Tong BD, Wu YJ \& Xiong W 2014 MicroRNA-29 mediates TGFbeta1induced extracellular matrix synthesis by targeting wnt/beta-catenin pathway in human orbital fibroblasts. International Journal of Clinical and Experimental Pathology 7 7571-7577.

Voloshenyuk TG, Landesman ES, Khoutorova E, Hart AD \& Gardner JD 2011 Induction of cardiac fibroblast lysyl oxidase by TGF-beta1 requires PI3K/Akt, Smad3, and MAPK signaling. Cytokine 55 90-97. (doi:10.1016/j.cyto.2011.03.024)

Wang B, Komers R, Carew R, Winbanks CE, Xu B, Herman-Edelstein M, Koh P, Thomas M, Jandeleit-Dahm K, Gregorevic P et al. 2012 Suppression of microRNA-29 expression by TGF-beta1 promotes collagen expression and renal fibrosis. Journal of the American Society of Nephrology 23 252-265. (doi:10.1681/ASN.2011010055)

Woodruff TK \& Shea LD 2007 The role of the extracellular matrix in ovarian follicle development. Reproductive Sciences 14 6-10. (doi:10.1177/1933719107309818)
Yang T, Liang Y, Lin Q, Liu J, Luo F, Li X, Zhou H, Zhuang S \& Zhang H 2013 miR-29 mediates TGFbeta1-induced extracellular matrix synthesis through activation of PI3K-AKT pathway in human lung fibroblasts. Journal of Cellular Biochemistry 114 1336-1342. (doi:10.1002/ jcb.24474)

Yao N, Yang BQ, Liu Y, Tan XY, Lu CL, Yuan XH \& Ma X 2010 Folliclestimulating hormone regulation of microRNA expression on progesterone production in cultured rat granulosa cells. Endocrine 38 158-166. (doi:10.1007/s12020-010-9345-1)

Received 17 March 2016

First decision 21 April 2016

Revised manuscript received 6 June 2016

Accepted 17 June 2016 